English Profile Journal. (2013), 3(1), Page 1 of 24, e4 (C) Cambridge University Press 2013 doi:10.1017/S2041536212000049

\title{
A corpus linguistic analysis of turn-openings in spoken academic discourse: Understanding discursive specialisation
}

\author{
Jane Evison School of Education, University of Nottingham \\ Jane.Evison@nottingham.ac.uk
}

\begin{abstract}
Recent corpus linguistic (CL) investigations of academic discourse (both written and spoken) have tended to use easily excisable lexical items and/or grammatical forms to determine what is 'special' about the language of academia, and to compare and contrast particular disciplines or subjects with each other. This study takes a different approach to characterising academic talk - beginning with position rather than item. It is predicated on the well-established tenet that a considerable amount of discursive activity occurs in the extremely elastic and highly charged openings of turns, a position in the discourse that is the nexus of textual and interpersonal obligation, risk and potential. It therefore presents the results of the systematic analysis of the openings of 13,337 turns taken by tutors and students in a range of common pedagogic encounters in the humanities and social sciences. A set of 'core' turn-openers is then identified so that further detailed contextualised analysis can be carried out, which includes comparison with a benchmark corpus of casual conversation. The results suggest that academic speakers start their turns with recognisably conversational items that show subtle, but regularised, discursive specialisations related to their reflexive relationship with the academic encounters in which they are uttered and which they help to create.
\end{abstract}

Keywords: academic discourse, university talk, turn-openers, interaction, turn-taking, discursive specialisation

\section{Introduction}

The English Profile Project (EPP) (http://www.englishprofile.org/) is concerned with improving descriptions of language use, and, with regard to spoken language, the English Profile Gournal has already addressed the notion of fluency (McCarthy 2010). I share the views expressed in that paper that in order for EPP research to best serve the improvement of the CEFR (Common European Framework of Reference) level descriptors, greater account needs to be taken of the ways in which speakers' discursive successes are jointly achieved. The position taken here is that robust descriptions of the features of spoken discourse need to be based on substantial samples of naturally occurring language, and that these descriptions should include the collaborative features of turn-taking and turn construction 
that are evidenced in specific types of interaction. This paper therefore presents and explores detailed linguistic description that focuses on talk in one specific context: the academic encounter. It uses transcribed data from lectures, seminars, group/individual tutorials, and $\mathrm{PhD}$ supervisions in the humanities and social sciences, and in particular, one position in that talk: the turn-opening. Although the approach is primarily corpus linguistic (CL), it also draws on other more established research traditions, specifically the groundbreaking descriptive work of Sinclair and Coulthard (1975) focusing on classroom talk, and insights into turn-taking and turn construction which have their origins in the Conversation Analysis (CA) approach of Sacks and Schegloff (e.g. Sacks et al. 1974; Sacks 1992; Schegloff 1982, 1996). It does this because the peculiar discursive nature of learning encounters makes a flexible approach to analysis necessary (Walsh 2006), and so that the investigation can take into account position in the turn and frequency simultaneously, something that conventional CL techniques are not usually able to do.

\section{Turn-openings: Contingent and messy}

The turn-opening is an excellent example of a position in the talk where the pressures of realtime communication are routinely dealt with by speakers who do not have time to stop and reflect on the exact items they have chosen to use. In the words of Brazil (1995: 11), 'we know that causing [speech] to happen is not always without its problems: our ability to put together what we want to say may not always be equal to the pressure to keep up with ourselves ... as listeners, too, we frequently feel ourselves under similar pressure'.) in extract 1 below, ${ }^{1}$ which is taken from a university tutorial, exemplifies the following issues: openings themselves are often not clearly heard (turn 8 begins with a 'best guess' transcription and turn 12 has two inaudible syllables at the beginning), one turn may slightly overlap or be latched on to the preceding turn (turns 9-12), and there may be hesitations and repetitions (turn 1), and false starts (turn 7). In addition, turn-openings often contain a range of items that are not conventionally considered as words, even though they may have the phonological characteristics of words and that may be difficult to transcribe (em in turn 1, for example), as well as small multi-functional items (right, okay in turns 5 and 7). And, of course, an opening may also be a closing if the turn is a single word or vocalisation (yeah in turn 9, for example), and the same form can be an opening/closing, but also preface a longer contribution (compare $m m$ in turn 11 and turn 13).

(1)

Turn File: IND02

$1<\$ \mathrm{~S} 1>\mathrm{Em} .<\$=>$ It $<\backslash \$=>$ it was certainly one that she's kept mentioning $\mathrm{t}=$ two or three times yeah

$2<\$ \mathrm{~T}>\mathrm{Mm}$. Mm. $<\$=>$ Because em you see $<\$ \mathrm{E}>$ knock on door $<\backslash \$ \mathrm{E}>$ you see you can work out your $<\backslash \$=>$ Come in.

$3<\$ S 2>$ Oh hi. Can I just hand you this. $<\$$ G3? $>$

$4<\$ T>$ Right.

$5 \quad<\$ S 2>$ That's right?

\footnotetext{
${ }^{1}$ Transcription conventions and filenames can be found in Appendix 1.
} 


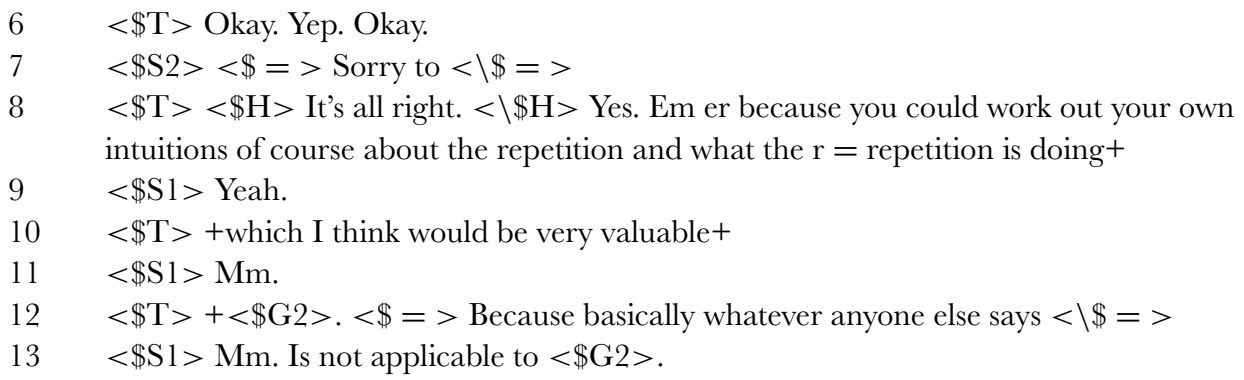

The complexities that exist around turn boundaries are perhaps most naturally a topic of interest to researchers investigating talk from a CA perspective, which attempts to understand talk from the point of view of the speakers at the time - an 'emic' perspective - and as social action. However, the relationship between turn-openings and the turn constructional unit (TCU) - what CA sees as the building block of the turn - has been problematic for CA researchers. In particular, Schegloff (1996) argues that the impact of the turn-opening is such that some of the items that occur there may in some way 'belong' to the whole turn, rather than the TCU in which they occur. This suggests that items which populate turn-openings in particular may have distinct discursive functions.

The related literature focusing on listener behaviour, especially the use of small non-floorgrabbing items commonly known as back-channels, a term first used by Yngve (1970), has been rather preoccupied with discussions about the nature of back-channelling itself (Yngve 1970; Gardner 1997), related implications for what is, and isn't, a full turn (e.g. Duncan \& Niederehe 1974; Schegloff 1982, 1996; Goodwin 1986; Stenström 1994; Gardner 1997), the complex relationship between body language, gaze, vocalisations, words, phrases and full clauses (Duncan 1972; Jucker 1986), the types of back-channels as well as the kinds of tokens used to encode them and the status of each as a back-channel (Tottie 1991; Gardner 1997). Another issue in the literature is the multi-functionality of such tokens, and their susceptibility to identification as discourse markers as well as back-channels. The affinity of discourse markers with the turn-initial position is long-established (see Schiffrin's seminal [1987] work), and the prolific literature associated with discourse marking - despite the tensions between different views (e.g. Fraser 1990, 1999; Schiffrin 2001; Blakemore 2002) is most insightful in terms of how it foregrounds the important co-ordinating and relational functions of markers.

Clearly, much has been written about the complexities of turn-openings, and most of it from a CA perspective - one which has traditionally used small datasets. The next section of this paper therefore moves on from the issues of multi-functionality/complexity highlighted by such research to consider the insights into turn-openings that CL investigation has thus far been able to provide.

\section{Corpus linguistic research into turn-openings}

CL is predicated on the automatic identification of regularity in language use. However, because the software suites used to carry out search tasks were typically designed to 
analyse written language with its established punctuation system and general 'tidiness', using such suites to search for repeated linguistic behaviour around messy turn-openings is not straightforward. In fact, the transitions between speakers are probably the most challenging position to investigate using automated techniques. Back in 1991, Sinclair, writing about the construction of the Cobuild corpus, observed that ' $[\mathrm{m}]$ ost corpora keep well away from the problems of spoken language - with some honourable exceptions' (pp. 15-16). Although the last twenty years has seen the development of increasing numbers of spoken corpora, I would argue that most CL studies do keep well away from the problems of turn-openings (with some honourable exceptions that I will discuss below).

The primary exception is Tao (2003), the first CL investigation of turn beginnings, which focuses on turn-initial items in 3,000 turns of American casual conversation, using the corpus analytical technique of concordancing to search for all new speaker tags. This procedure results in the identification of all examples of a particular item in a corpus in the form of a number of concordance lines, with the searched-for item - in this case the new speaker tag - displayed as the central or node item. Tao takes a broad view of what constitutes a turn (anything separated by speaker tags) rather than using a strict CA interpretation, which would involve the identification of turn constructional units, and the classification of back-channels as not being full turns. The results show that 60 per cent of the turns are opened by the twenty most frequently occurring forms, and that in the initial position 'lexical forms and vocalizations dominate' (p. 190). Tao also looked at the frequency with which these forms occurred turn-initially compared with other positions in the talk, with the proviso that his approach didn't take into account the different functions of items (for example, right can act as an adjective or an adverb, as well as being a discourse marker). Certain items did show a clear preference for the turn-initial position (the majority of the occurrences of $m h m$, uh-huh, oh, yeah, okay were turn-initial), whilst others, such as the, despite being very frequent turninitially (and sentence-initially in written corpora), were actually less likely to occur initially than elsewhere in the discourse (just 3 per cent of the occurrences of the in Tao's data were turn-initial).

CL studies on listenership in casual conversation (McCarthy 2002, 2003; O'Keeffe \& Adolphs 2008) have also provided useful insights into the turn-opening position. The approach taken by McCarthy $(2002,2003)$ in related studies (which did not include nonverbal tokens) is not to try to distinguish between back-channels and non-back-channels, but to instead distinguish between 'minimal response tokens' ('single-word response moves') and 'non-minimal' ones, the latter referring to 'yes-plus words' which 'do more than just acknowledge and confirm' (2002: 49). Thus minimal response tokens (yeah, yes) are contrasted with non-minimal ones (e.g. exactly, absolutely) which encode greater relational and evaluative meaning. McCarthy's studies report the high frequency of non-minimal response tokens, and the use of 'doublets' and 'triplets' (combinations of response tokens that are also routinely used individually such as great lovely or cool right fine), especially to mark closings or other transitions in the talk, and McCarthy (2003: 38) argues that the turn-initial position is the 'the locus of choice where speakers frequently select items which contribute to the non-transactional stratum of the talk, and where [a] set of "small" items does its work of supporting, converging, bridging and facilitating transitions'. These two related studies use automatically generated frequency lists from two large corpora of British and American English rather than new 
speaker tags as a starting point, allowing potential response tokens (excluding non-word tokens such as $\mathrm{mm}$ and $\mathrm{mhm}$ ) to be identified based on frequency criteria, and then followed by the non-automatic analysis of randomly generated concordance lines to identify when those items have responsive functions. Both studies highlight that although there are small lexical variations between British and American English, in terms of response tokens, the two varieties 'have more in common than that which separates them' (2002: 69). This kind of commonality was also reported by O'Keeffe and Adolphs (2008) in a comparison of Irish and British English.

Large-scale CL studies of academic talk have tended to focus on variation across academic levels and disciplines (see Biber [2006] for the most comprehensive set of studies, and also Csomay [2007]) and have not focused on the turn-opening specifically. In fact, these variation studies have not been able to differentiate well between classroom teaching and other spoken registers, such as study groups, which researchers may intuitively feel are more highly involved (Biber 2006). In fact, Biber (2006: 223) remarks upon the considerable 'extent to which linguistic characteristics are shared across all spoken registers, regardless of differences in audience, interactivity, or communicative purpose' [original emphasis]. Other smaller-scale studies of academic talk, however, have looked at academic talk in relation to the turnopening. Farr (2003) is small study which looks at engaged listenership in a corpus of 70,000 words of university tutorial data within the discipline of education. Like McCarthy, Farr uses the distinction between minimal and non-minimal response tokens, but also includes a third category of overlaps and interruptions, which are seen by Farr as 'show[ing] affective engagement as the speakers are engaged emotionally with both the talk content and the face needs of the other speaker' (p. 81). So, even in institutional talk, the turn-opening is characterised as a site of engagement with non-transactional needs, although Farr also concludes that listenership tokens in academic talk have a more evaluative/critical function than they would in casual conversation. This kind of listenership specialism is also reported by Gardner (2007) in a CA study of medical discourse, which suggests that engaged listenership tokens such as right have very specific functions in institutional encounters where there is 'a lot of information transfer' (p. 336). In the domain of academia, Schleef (2009) provides a comparison of the academic style of German and American academics in lectures and interactional classes in the humanities and natural sciences. Part of the study involves a comparison of both back-channel and turn-initial response token use across the two corpora. Schleef reports that the results of this analysis are difficult to interpret but does conclude that '[i]nstructors and students fulfill particular discourse roles and use structures that best serve these roles' (Schleef 2009: 1117).

The literature reviewed in this section, and the one which preceded it, has shown that whilst the turn-opening has received some research attention, there is certainly more work to be done. CA-oriented studies which use small amounts of data have certainly flagged up how complex and pivotal turn-openings are. CL studies, with the exception of Tao (2003), have tended to focus on response and listenership and have mostly concentrated on casual conversation, with very little interest in academic turn-openings. However, the literature also suggests that if we can better describe and understand the academic turn-opening, we will be better informed about how academic discourse is constructed. With this in mind, the next section introduces the data and methodology used in the current study. 
Page 6 of $24 \mid$ JANE EVISON

\section{Data and methodology}

The data used in this study form part of the much larger Cambridge English Corpus (formerly the Cambridge International Corpus). These data are contained within the CANCODE corpus that was developed at The University of Nottingham, UK, and was funded by Cambridge University Press, with whom sole copyright resides. The spoken interactions were recorded in a wide variety of mostly informal settings across the islands of Britain and Ireland. The project continues to have considerable impact on both teaching and research; example works that utilise the CANCODE data include McCarthy (1998), Carter and McCarthy (1998, 2006), Carter (2004), O'Keeffe et al. (2007), and Carter et al. (2011). Two sub-corpora of CANCODE were used for this study. The first is a corpus of more than 13,000 different turns of academic discourse totalling just over a quarter of a million words recorded over seven types of teaching encounter or 'Academic Discourse Event' (ADE) in the humanities and social sciences. In this study, this sub-corpus is known as CANCAD (The Cambridge and Nottingham Corpus of Academic Discourse). Table 1 is an overview of the data.

Table 1 Academic Discourse Events in CANCAD.

\begin{tabular}{lrrrc}
\hline \hline Activity & Number & Words & Turns & Turns per 1k words \\
\hline Class & 2 & 7,646 & 229 & 29.93 \\
Seminar & 10 & 87,120 & 4,538 & 52.09 \\
Lecture & 10 & 89,377 & 2,862 & 32.02 \\
Group tutorial & 4 & 25,003 & 1,224 & 48.96 \\
Individual tutorial & 4 & 13,024 & 800 & 61.44 \\
PhD supervision & 3 & 23,660 & 2,954 & 124.85 \\
PhD upgrade meeting ${ }^{2}$ & 1 & 5,960 & 730 & 122.48 \\
Total & 34 & 251,790 & 13,337 & (mean) 67.40 \\
\hline \hline
\end{tabular}

For comparative purposes, this study uses CANCSOC, a second sub-corpus also drawn from CANCODE, which is composed of 2,687,505 words spread across 500 files representing data from the socialising and intimate conversations of the corpus, and which has been used in previous comparative analysis (e.g. Evison et al. 2007). Neither sub-corpus used in this study was tagged for part of speech, although the mark-up of CANCAD was modified so that types of encounter, as well as tutor and student contributions, could easily be identified.

A three-stage analytical process was carried out using Wordsmith Tools (Scott 1999):

1. The generation of frequency lists for the most commonly occurring turn-initial forms in the data based on the concordance search results for all new speaker tags, the same method used by Tao (2003). A very small portion of the search results are exemplified in Figure 1. This initial list was then right-sorted so that all turn-initial forms could be identified (Figure 2) and all forms occurring more than forty times were extracted. ${ }^{3}$

\footnotetext{
${ }^{2}$ Students often begin doctoral studies in the UK by registering for an MPhil. After a year of full-time study (or two years part-time) they upgrade to $\mathrm{PhD}$ status at an interview.

${ }^{3}$ For a detailed exemplification of this technique in relation to the CL analysis of academic talk, see Evison (2010: 130-33).
} 


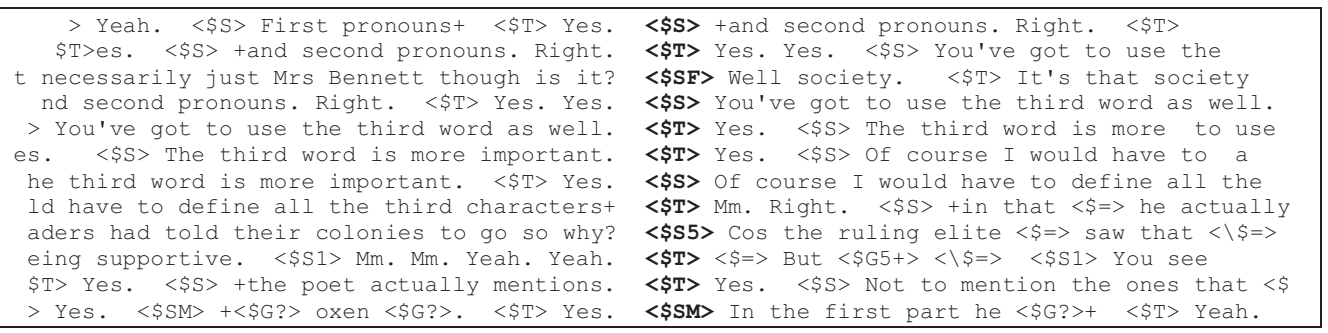

Figure 1 Example concordance lines from CANCAD (unsorted).

\begin{tabular}{|c|c|}
\hline 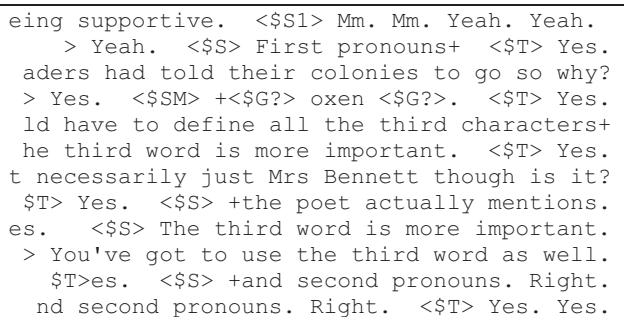 & 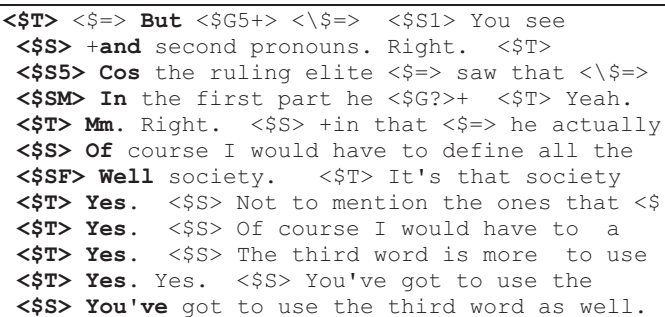 \\
\hline
\end{tabular}

Figure 2 Example concordance lines from CANCAD (right-sorted).

A frequency list for all these forms in any position in the data was also generated, so the frequency with which items occurred initially could be calculated. This is referred to as turn-initial 'priming', after Hoey (2005). ${ }^{4}$

2. The generation of a list of the most frequently occurring syntactically independent items in the data (what Tao [2003] calls turn-openers) arrived at by manual analysis of all the concordance lines generated in step 1 , further divided into those uttered by tutors and those by students.

3. Further detailed analysis of the items generated in step 2, including comparisons with their frequency in casual conversation, across tutor and student talk, and across different kinds of ADEs. In addition to frequency and concordance analysis, this stage included detailed analysis of the transcripts themselves.

\section{Results and discussion}

\subsection{What are the most common turn-initial forms and how likely are they to occur initially?}

The initial concordance search for all new speaker tags in CANCAD yielded a list of forty-six forms that occurred more than twenty times turn-initially. ${ }^{5}$ These raw frequencies are shown

\footnotetext{
${ }^{4}$ Hoey (2005) refers to the propensity with which an item occurs in a certain position in the discourse as 'lexical priming'. Although he is talking about written language, he suggests that 'there is every reason to suppose that similar claims can be made about the beginning [...] of speech turns' (p. 151).

${ }^{5}$ As with other studies of this kind, an arbitrary cut-off point was chosen - in this case, only items which began turns on more than 20 occasions out of the 13,000+ turns were included.
} 
Page 8 of $24 \mid$ JANE EVISON

Table 2 Turn-initial forms in CANCAD.

\begin{tabular}{|c|c|c|c|c|c|c|c|}
\hline No & Item & $\begin{array}{c}\text { Raw } \\
\text { frequency }\end{array}$ & $\begin{array}{c}\% \text { turn- } \\
\text { initial }\end{array}$ & No & Item & $\begin{array}{c}\text { Raw } \\
\text { frequency }\end{array}$ & $\begin{array}{c}\% \text { turn- } \\
\text { initial }\end{array}$ \\
\hline 1 & yeah & 1,339 & 55.56 & 24 & if & 76 & 5.52 \\
\hline 2 & $\mathbf{m m}$ & 1,063 & 80.90 & 25 & there* & 74 & 4.43 \\
\hline 3 & laughter & 620 & 76.45 & 26 & they* & 70 & 3.93 \\
\hline 4 & $\mathbf{m h m} / \mathbf{m m} \mathbf{m m}$ & 549 & 91.50 & 27 & $\cos$ & 65 & 17.52 \\
\hline 5 & and & 522 & 8.26 & 28 & all & 64 & 5.00 \\
\hline 6 & $\mathrm{I}^{*}$ & 498 & 9.13 & 29 & which & 59 & 4.93 \\
\hline 7 & yes & 490 & 56.58 & 30 & now & 54 & 7.10 \\
\hline 8 & right & 477 & 37.95 & 31 & he* & 53 & 3.67 \\
\hline 9 & erm/er/em & 417 & 8.94 & 32 & we* & 52 & 2.91 \\
\hline 10 & it* & 313 & 4.68 & 33 & like & 51 & 4.57 \\
\hline 11 & but & 280 & 13.58 & 34 & this & 51 & 2.60 \\
\hline 12 & so & 276 & 13.09 & 35 & or & 49 & 3.86 \\
\hline 13 & well & 261 & 27.94 & 36 & how* & 47 & 7.65 \\
\hline 14 & you* & 253 & 3.39 & 37 & do & 42 & 3.11 \\
\hline 15 & that* & 245 & 3.94 & 38 & good & 40 & 11.73 \\
\hline 16 & no & 238 & 28.07 & 39 & sorry & 34 & 23.29 \\
\hline 17 & okay & 219 & 25.32 & 40 & why* & 34 & 8.29 \\
\hline 18 & oh & 182 & 58.33 & 41 & she* & 31 & 5.76 \\
\hline 19 & the & 177 & 1.62 & 42 & ah & 25 & 51.02 \\
\hline 20 & because & 131 & 13.75 & 43 & where* & 23 & 5.71 \\
\hline 21 & in & 108 & 2.56 & 44 & does & 20 & 5.09 \\
\hline 22 & what* & 107 & 4.48 & 45 & exactly & 20 & 18.52 \\
\hline 23 & is & 105 & 2.48 & 46 & isn't & 20 & 5.06 \\
\hline
\end{tabular}

* Includes closely related forms (e.g. I, I've, I'll, etc., he, he'll, etc., why, why's, what, what've, etc.).

in Table 2, along with a measure of each form's turn-initial priming - its propensity to occur turn-initially expressed as a percentage of its total occurrences.

Without more detailed analysis of the sort presented in further sections, we cannot be sure about how these forms behave, but, supported by the established literature relating to the turn-initial position, there is a clear indication that small utterances (e.g. $\mathrm{mm}, \mathrm{mhm}$, yeah) are important turn-initially, as are forms which are likely to be operating at a discourse level rather than as within-sentence conjunctions (and, but, so, well, because, cos), and a small number of forms that are likely to be operating as responsive items rather than as adjectives or adverbs within clauses (good, right, well, exactly). There are grammatical (function words) in this list, most notably personal pronouns ( $I, i t$, you and we are the most frequent of these), wh-question words and forms of two delexical verbs $(b e$ and $d o$ ). The top half of the list shows a noticeable bias towards forms that we would expect to have discourse functions, and in the list as a whole there are seven items (shown in bold) which occur more often in a turn-initial position than anywhere else in the discourse. Finally, of all forty-six forms in the list, the one that is least likely to occur turn-initially, despite the frequency with which it begins written 
Table 3 Top twenty turn-initial forms: Comparison across corpora.

\begin{tabular}{lrrr}
\hline \hline & $\begin{array}{c}\text { Number } \\
\text { of turns }\end{array}$ & $\begin{array}{l}\text { Top twenty } \\
\text { forms (raw } \\
\text { frequency) }\end{array}$ & \% of all turns \\
\hline CANCAD & 13,337 & 8,550 & 64.11 \\
CANCSOC & 374,819 & 224,489 & 59.89 \\
Tao (2003) & 3,227 & 1,919 & 59.43 \\
\hline \hline
\end{tabular}

sentences, is the. Just as Tao (2003) found, the, whilst making it into the top twenty because of its high frequency, is actually less likely to occur initially than elsewhere in the discourse. So, we could say, using Hoey's (2005) term, that the is therefore not 'primed' to occur turn-initially as more often than not it doesn't appear first. ${ }^{6}$ The relative lack of affinity that the shows with the turn-opening suggests that it is routinely displaced by items with a discourse function. Their use is necessitated by the pivotal role that the turn-opening has in segueing between prior and upcoming talk. A bald turn-initial the, on the other hand, is likely to be discursively troublesome unless it is part of a chunked sequence such as the thing is, or is an answer to a question as in the sequence What's today's date? The twentieth, I think.

In terms of just how regular the turn opening is, the results of this study display a striking similarity with those reported by Tao (2003), who focused only on the top twenty most frequent forms. Table 3 shows that for this academic data, the top twenty most frequent forms open 64 per cent of the turns in the corpus, whilst for CANCSOC, the twenty most frequent forms of all account for 60 per cent of all turns - the same proportion reported by Tao.

Thus, this initial analysis points to regularised, discourse-oriented behaviour at turnopenings in academic talk. The next stage of the analysis isolates all the independent turn-initiators, or 'turn-openers' (Tao 2003), in other words, items which are syntactically independent of the talk that follows them.

\subsection{What are the most common turn-openers?}

The extraction of the turn-openers in CANCAD was carried out by manual analysis of concordance lines for all the new speaker tags in the corpus to determine which items were syntactically independent turn-openers. Thus, some forms from Table 2 were discounted entirely (the never occurred independently) or instead were included in the counts for frequently occurring phrasal or clausal turn-openers: for example, of the original 498 occurrences of $I$, only 182 remained as constituents of I think, I mean and I know, whereas 475

\footnotetext{
${ }^{6}$ However, establishing a reliable measure of turn-initial priming is very difficult because of the variation in turn length (see Evison, 2008, Schleef, 2009). Although turn-initial priming is an attractive concept, it is not a straightforward one to write about with any certainty.
} 
Page 10 of 24 JANE EVISON

Table 4 Independent turn-openers: Raw frequency.

\begin{tabular}{|c|c|c|c|c|}
\hline No & Item & GANCAD & GANGAD-T & GANGAD-S \\
\hline 1 & yeah & 1,339 & 634 & 705 \\
\hline 2 & $\mathrm{~mm}$ & 1,063 & 479 & 584 \\
\hline 3 & laughter & 620 & 30 & 590 \\
\hline 4 & $\mathrm{mhm}$ & 549 & 356 & 193 \\
\hline 5 & and & 522 & 246 & 276 \\
\hline 6 & yes & 490 & 396 & 94 \\
\hline 7 & right & 475 & 364 & 111 \\
\hline 8 & erm & 417 & 163 & 254 \\
\hline 9 & but & 280 & 149 & 131 \\
\hline 10 & so & 264 & 146 & 118 \\
\hline 11 & well & 260 & 114 & 146 \\
\hline 12 & no & 234 & 98 & 136 \\
\hline 13 & okay & 219 & 178 & 41 \\
\hline 14 & oh & 182 & 79 & 103 \\
\hline 15 & because & 131 & 64 & 67 \\
\hline 16 & I think & 100 & 44 & 56 \\
\hline 17 & $\cos$ & 65 & 38 & 27 \\
\hline 18 & that's right & 64 & 46 & 18 \\
\hline 19 & I mean & 62 & 40 & 22 \\
\hline 20 & now & 54 & 46 & 8 \\
\hline 21 & you know & 53 & 38 & 15 \\
\hline 22 & all right & 49 & 39 & 10 \\
\hline 23 & or & 49 & 28 & 21 \\
\hline 24 & good & 37 & 34 & 3 \\
\hline 25 & sorry & 34 & 24 & 10 \\
\hline 26 & $\mathrm{ah}$ & 25 & 11 & 14 \\
\hline 27 & exactly & 20 & 12 & 8 \\
\hline \multirow[t]{4}{*}{28} & I know & 20 & 7 & 13 \\
\hline & Total & 7,677 & 3,903 & 3,774 \\
\hline & All turns & 13,337 & 6,345 & 6,992 \\
\hline & Percentage & 57.56 & 62.51 & 54.98 \\
\hline
\end{tabular}

of the original 477 occurrences of right remained (the two discounted were not independent as they were found to be functioning as pre-modifiers as in right the way down).

The results are shown in Table 4, which includes the frequency of each item in tutor and student turns (columns CANCAD-T and CANCAD-S, respectively) in addition to overall.

The revised figures for turn-initial regularity now show that in terms of turn-opener use, both tutor and student turns show noticeably regularised behaviour. The remainder of this paper will explore several groups of items from this list, which, it will be argued, show particular discursive behaviour that is specialised to the needs of the institutional context in which the talk occurs, and the various responsibilities of the tutors and the students. 
UNDERSTANDING DISCURSIVE SPECIALISATION |Page 11 of 24

\subsection{Response and responsibility: The discursive behaviour of $\mathrm{mhm}$, yes, right and okay in academic talk}

The findings presented in this section relate to a small group of responsive items ( $\mathrm{mhm}$, yes, right and okay) that work hard in all types of $\mathrm{ADE}$, although not as hard in terms of turninitial frequency alone as yeah, $\mathrm{mm}$ and laughter, ${ }^{7}$ which will be discussed later in conjunction with other turn-openers where a better idea of their discourse functions can be seen. The academic 'potential' of mhm, yes, right and okay (along with the turn-openers discussed in the next section too) is evidenced by their distribution across the turns of tutors and students, and in comparison with casual conversation. Turn-initially, they are more frequent in academic talk than in casual conversation, but are found more often in the turn-opening position in tutor talk than in student talk. This distribution, this paper argues, makes these items a fundamental part of what makes this talk 'academic'. These small items work alongside the types of lexis and syntax that other studies (e.g. Poos \& Simpson 2002; Biber 2006; Nesi \& Basturkmen 2006; Buttery et al., in press) have shown to be characteristic of academic talk.

Automatically generated frequency and keyword lists of the kind typically used in CL would not, however, have identified right and yes as significant in academic talk, as Figure 3 shows. It is not until turn-initial frequency is considered in relation to speaker role (Figure 4), that a salient pattern in academic talk can be observed. This more nuanced second comparison shows us that when uttered turn-initially, mhm, yes, right and okay are much more frequent in academic talk, although they are not distributed equally across the turn-openings of tutors and students; tutors clearly use these items more frequently than students.

Further investigation of these items in context shows that their use is strongly connected with the discursive demands of two key institutional goals in academic talk. These are getting the immediate business of teaching and learning done effectively, and supporting ongoing research and study, and both of them place considerably more 'academic discourse responsibility' on the tutors rather than the students (Evison 2008). (1) shows yes, okay and right occurring during a tutorial. Both the tutor and the student are orienting to their respective discourse roles of advice-giver and advice-receiver - the tutor's use of yes forming part of a longer sequence (Yes. Good) reminiscent of the kinds of transaction boundary marker identified by Sinclair and Coulthard (1975), where the transition from one 'transaction' or phase of classroom activity to another is signalled, whereas the student's use of okay and right does not overtly shape the progress of the discourse but simply signals acknowledgement that the tutor is bringing the talk to a close.

And, in (2), from a literature seminar, we can see how three successive uses of $\mathrm{mhm}$ by the tutor signal that the student should continue, even after the student's ideas are framed as a question in turn 3, which, whilst it may be rhetorical, may also be signalling that the student is happy to relinquish the floor. This is the kind of supportive behaviour that Farr (2003) identifies as 'engaged listenership' in tutorial contexts.

${ }^{7} \mathrm{mhm}$, yes, right and okay were considered separately from yeah, $\mathrm{mm}$ and laughter as they showed different overall distribution. Each of the first four items was more frequent at the beginning of tutor turns than student ones, whereas each of the second three showed the opposite pattern (see Table 4). 
Page 12 of 24 JANE EVISON

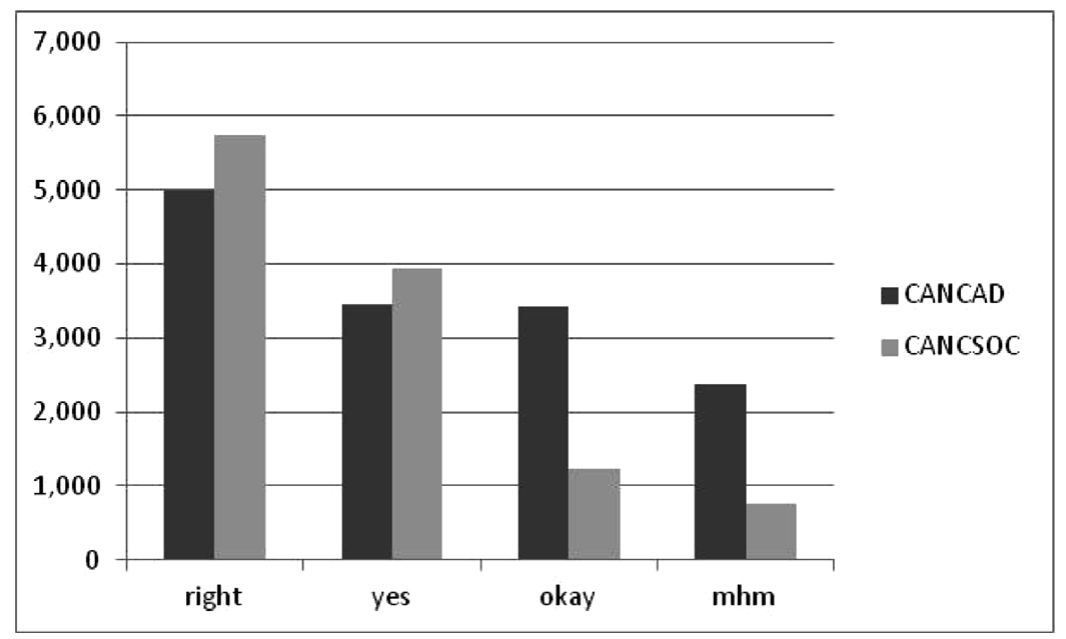

Figure 3 Frequency per $1 \mathrm{~m}$ words (any position)

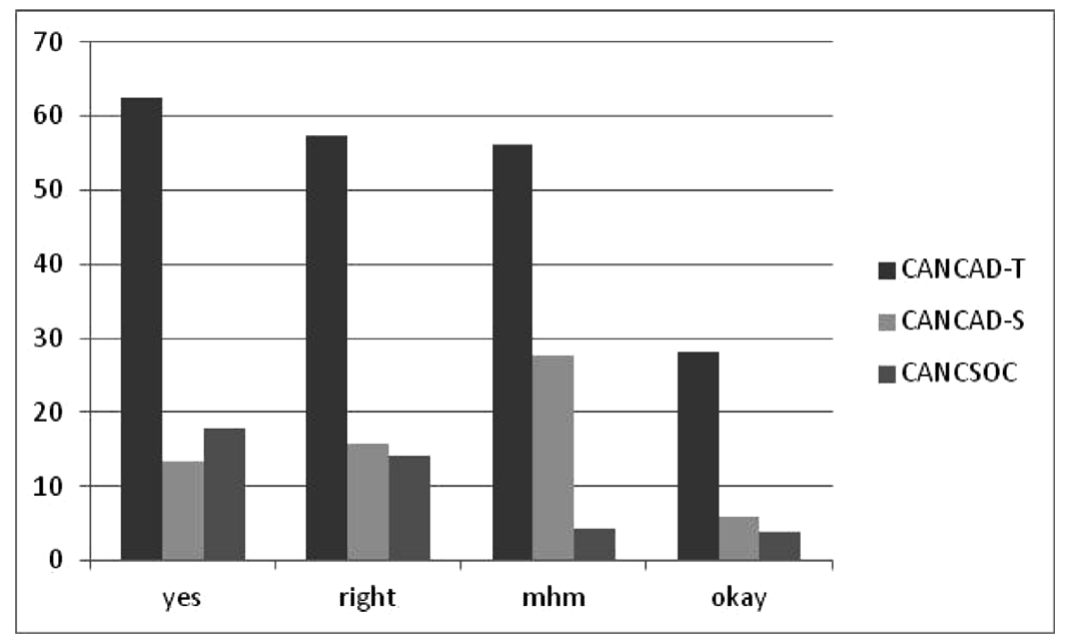

Figure 4 Turn-initial frequency (per $1 \mathrm{k}$ turns)

(2)

Turn File: IND03

$1<\$ T>$ But it is an adverbial er within that clause. $<\$=>$ So that's your $<\backslash \$=>$

$2<\$ S>$ Yeah. that's what I thought but I wasn't quite sure.

$3<\$ T>$ Yes. Good.

$4<\$ S>$ Okay

$5<\$ T>$ Yeah. You're doing fine.

$6<\$ \mathrm{~S}>$ Right. $<\$ \mathrm{E}>$ laughs $<\backslash \$ \mathrm{E}>$ 
UNDERSTANDING DISCURSIVE SPECIALISATION |Page 13 of 24

Table 5 Functions of yes/right/okay + expanded content in CANCAD-T: raw frequency.

\begin{tabular}{|c|c|c|c|c|c|c|}
\hline & \multicolumn{2}{|c|}{ yes } & \multicolumn{2}{|c|}{ right } & \multicolumn{2}{|c|}{ okay } \\
\hline & $\mathrm{n}$ & $\%$ & $\mathrm{n}$ & $\%$ & $\mathrm{n}$ & $\%$ \\
\hline Followed by major footing shift/transaction boundary & 0 & 0 & 3 & 6.67 & 10 & 30.3 \\
\hline Followed by summary/extension of prior contribution & 89 & 100 & 17 & 37.78 & 11 & 33.33 \\
\hline Followed by elicitation of student contribution & 0 & 0 & 25 & 55.56 & 12 & 36.36 \\
\hline Total & 89 & 100 & 45 & 100 & 33 & 100 \\
\hline
\end{tabular}

(3)

Turn File: SEM08

$1<\$$ S5 $>$ And at the end Sally's changed. And it's all very

$2 \quad<\$ T>$ Mhm.

$3<\$ S 5>$ you kno $=$ who's changed? Who have actually ch $=$ have any of them

changed?

$4 \quad<$ T $>$ Mhm.

$5<\$$ S5 $>$ She's still got her theories about+

$6 \quad<\$ T>$ Mhm.

$7 \quad<$ S5 $>$ +having to know everybody.

(3) also exemplifies $\mathrm{mhm}$ in its preferred discursive environment: as the first and only item in a turn. Just over 70 per cent of its occurrences are as a stand-alone response token (i.e. as sole items in a turn), and when it is followed by another item this is most likely to be another $\mathrm{mhm}$ only. However, yes, right and okay, although sometimes occurring as stand-alone response tokens, are more likely than not to be followed by expanded content - in other words the turns that they begin tend to function as more than short responsive contributions. Here, the first of these three types of occurrence (yes/right/okay + expanded content) will be examined.

In order to investigate the behaviour of these items, the concordance lines for all occurrences of 'yes/right/okay + expanded content' were analysed and assigned to discursive categories. ${ }^{8}$ Table 5 details the results of this analysis, showing that three discursive categories were identified based on the categorising of shifts in the discourse. The first category - major footing shift/transaction boundary - brings together Sinclair and Coulthard's (1975) notion of signalled transitions from one 'transaction' or activity phase to another and Goffman's (1981) work on 'footing', where there is a change in participants' alignment to themselves 'and the others present which is expressed in the way that [they] manage the production or reception of an utterance' (p. 128). The shifts in the second - in which yes/right/okay are followed by a summary or extension of a prior contribution - are identified by topical progression (Brown and Yule 1983; Gardner 1987), and are not as major as in the first category. The third category contains examples where another contribution is required (either from the

\footnotetext{
${ }^{8}$ Occurrences where these openers were immediately followed by other discourse items such as but, well and so were not analysed further at this point because, in these cases, the initial openers were considered to be functioning as more minimal tokens of acknowledgement (McCarthy, 2002, 2003; O'Keeffe et al., 2007), the upcoming discourse items carrying the bulk of the work of discursive signalling.
} 
Page 14 of 24 JANE EVISON

same speaker the tutor is responding to, or a different one) - from an exchange structure perspective this can be seen as a Follow up/Initiation move. In all cases, the tutor is using discourse items to signal the transitions in the forthcoming talk.

We can see from this breakdown that both right and okay have a broader range of functions than yes, which appears prior to more minor topic shifts occasioned by the summary, or reformulation of a previous contribution, rather than a complete change of topic or activity as in (4) where in turn 3 the turn-opener yes is followed by an expansion of the student's previous contribution, which is recast more 'academically': existential there followed by three heavily modified noun phrases (a shift of votes, quite a lot of voter volatility and perceived self-interest).

\section{(4)}

Turn File: GRP01

1 (I) $\$ \mathrm{~T}>[\ldots]$ What about the decline of the communists? How best can that be explained in the eighties. I know that I'm coming a little bit now but clearly they've suffered in the elections in the eighties.

2 (R) $\$$ S4 $>$ Many of them switched their vote to the F N.

3 (F) $\$ \mathrm{~T}>$ Yes. There was a there was a shift of votes as I say and quite a lot of voter volatility in the particularly in the second half of the eighties. They switched because of perceived self interest $[\ldots]$

In (5) below, we can see an example of the subtly different functions of okay and right in a sociolinguistics seminar in which both okay and right are followed by elicitation of student contributions. In turn 1, turn-initial okay closes down the previous topic and is followed by an overt shift to a new one (let me just try something out here), okay being used to flag up an important transition in the talk - a kind of 'verbal waving', in the words of Swales and Malczewski (2001) - whereas turn-initial right in turn 3 allows the student's previous contribution to stay in topical focus but be subjected to academic challenge. The overall pattern evident here is the Initiation Response Follow-up/Initiation (IRF/I) pattern that Sinclair and Coulthard (1975) identified as crucial to primary-level academic encounters and which is still considered to be fundamental to the construction of all kinds of learning encounters (Walsh 2006).

(5)

$\begin{array}{lll}\text { Turn } & \text { File: SEM03 } & \\ 1 & <\$ T>\text { Okay. That's the latest method. Oh lovely. Yeah? All right let } & \text { Follow- } \\ & m=\text { let me let me just try something out here. Erm this is a couple } & \text { up } / \text { Initiation }^{2} \\ & \text { man and woman. Right. Don't you tell me. Which one is the woman? } & \\ 2 & <\$ S F>\text { The first one is the man. }<\$=>\text { The second is }<\mid \$=> & \begin{array}{l}\text { Response } \\ \text { F }^{2}\end{array} \\ 3 & <\$ \mathbf{T}>\text { Right. You're very sure about that? } & \begin{array}{l}\text { Follow- } \\ \text { up }^{2} / \text { Initiation }^{3}\end{array} \\ 4 & <\$ S F>\text { This type of thing }[\ldots] & \text { Response }^{3}\end{array}$

The comparative data shown in Table 5 suggest that there are subtle differences in the discursive function of yes, right and okay at turn-openings. Okay has the most even 


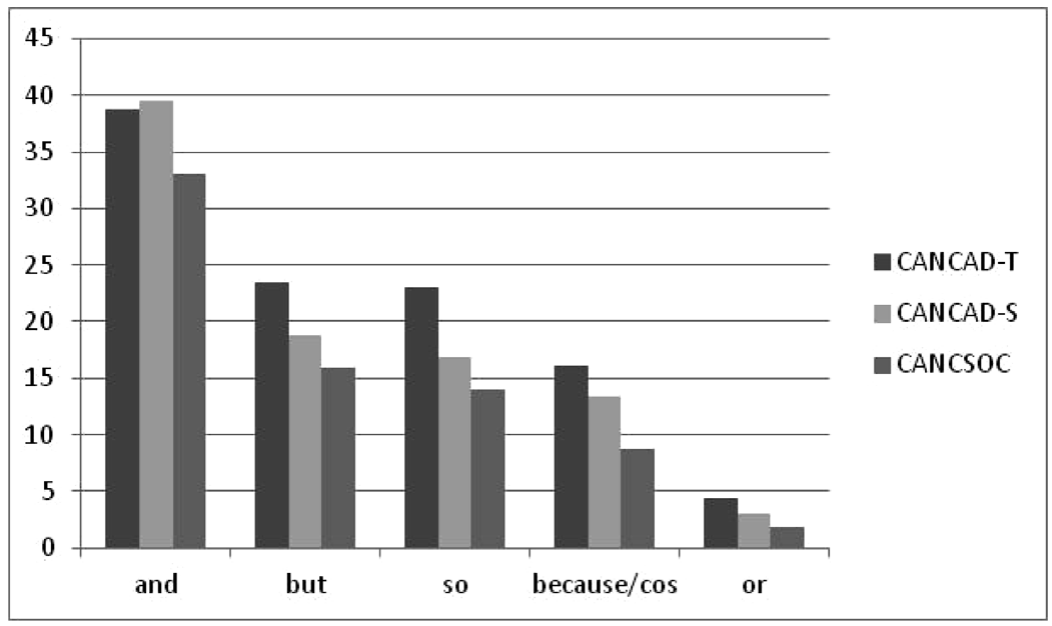

Figure 5 Textual turn-openers: frequency per $1 \mathrm{k}$ turns.

distribution across the three functions, suggesting that in academic talk it is the most 'allpurpose' responsive item of the three. Yes appears to have a stronger epistemic confirmatory function (Gardner 2007) than right, summarising and extending prior contributions, whilst right has all three functions, but with a preference for signalling the elicitation of student contribution for further exploration and challenge. In this case, it seems that right has more of a holding function and less of a confirmatory one. This makes it particularly useful in academic encounters where ideas are generated, explored and challenged.

\subsection{Managing the textual demands of academic talk}

Another set of turn-openers (and, but, so, because/cos, or) were found to have the same overall distribution pattern to yes, mhm, right and okay, as we can see in Figure 5. These can be characterised as textual turn-openers, in comparison with $\mathrm{mhm}$, yes, right and okay, which are more strongly responsive in nature. However, as with $\mathrm{mhm}$, yes, right and okay, these more textually oriented items have a higher frequency in CANCAD than in CANCSOC, with a strong tendency to be more frequent at the beginnings of tutor rather than student turns.

Further concordance analysis reveals that these textual turn-openers are regularly preceded by small contributions from the non-primary speaker, and that a pattern, exemplified in (6), emerges. This pattern relates to the three most frequent turn-openers in CANCAD ( $\mathrm{mm}$, yeah and laughter), which have not yet been discussed.

In fact, detailed analysis of all occurrences of turn-initial and, but, so, because/cos and or suggests that these turn-openers are regularly supported by small contributions - given that the mean 
Page 16 of 24 JANE EVISON

(6)

Turn

1 Primary speaker contribution

2 Non-primary speaker contribution

3 Primary speaker contribution
File: LEC02

$<\$ \mathrm{~T}><\$=>[\ldots]$ There er there is or isn't a contract depending on analysis of offer and acceptance and agreement. And that's one question.

$<\$ S 2>$ Mm.

$<\$ T>$ But if there is one and the term's there then we'd have to look at the reasonableness criteria. [...]

turn length in CANCAD is just under nineteen words per turn, compared with seven in CANCSOG, it not surprising that this support is regularly given. (7) exemplifies this further:

(7)

Turn File: UPG01

$1<\$ S>$ Or no you have a second character but it's all through the the the $<\$ G 2>$ of the I character. Right. $\mathrm{O}=$ of the $<\$ \mathrm{G}$ ? $>$.

$2<\$ T 2><\$ G$ ? $>$.

$3<\$ S>$ So you don't have like in in that er er poem that you er the lines you read of Auden. The fear that they're+

$<$ T2 $>$ Mm.

$<\$ S>+$ that you actually have two people talking. You don't have that. So I was looking for that +

$6 \quad<\$ 2>\mathbf{M m}$.

$7 \quad<$ S $>+$ and I couldn't find an answer of how I was going to approach this discourse. But that the purpose of I think down here of the work was initially was to er establish that there was a dialogue happening within the sonnet and how was this done.

$8<\$ T 2>$ Mm

$9 \quad<\$ S>$ And $[\ldots]$

These kinds of long turns which favour sustained topical focus and the examination of ideas and incremental build-up of analysis are supported by participants who are not the primary speaker, but whose short contributions support the extended talk of others. This observation is not new, and the supportive work of non-primary speakers (often known as back-channelling, as we saw earlier), is well documented, both in academic talk (e.g. Farr 2003) and in casual conversation (McCarthy 2010). However, it is by focusing on the inter-turn clusters that evidence of jointly produced academic talk - talk that is 'co-constructed' (Jacoby and Ochs 1995) - can be found. In fact, Figure 6 shows that certain combinations of items such as $m m$ and (shown in turns $6 / 7$ and 8/9) are more frequent across pairs of turn-openings than within single ones.

This section, and those which have preceded it, have shown that, if we look at a large enough sample of turn-openings, we can see patterns which suggest there is subtle discursive specialisation at the beginnings of turns which is contingent on the specific demands of academic talk, especially the shaping of academic argument, the encouragement and support of academic instalments, and the subtle (or not so subtle) shaping of student contributions by their tutors. So, although yeah and $\mathrm{mm}$ are not more frequent turn-initially in academic talk 


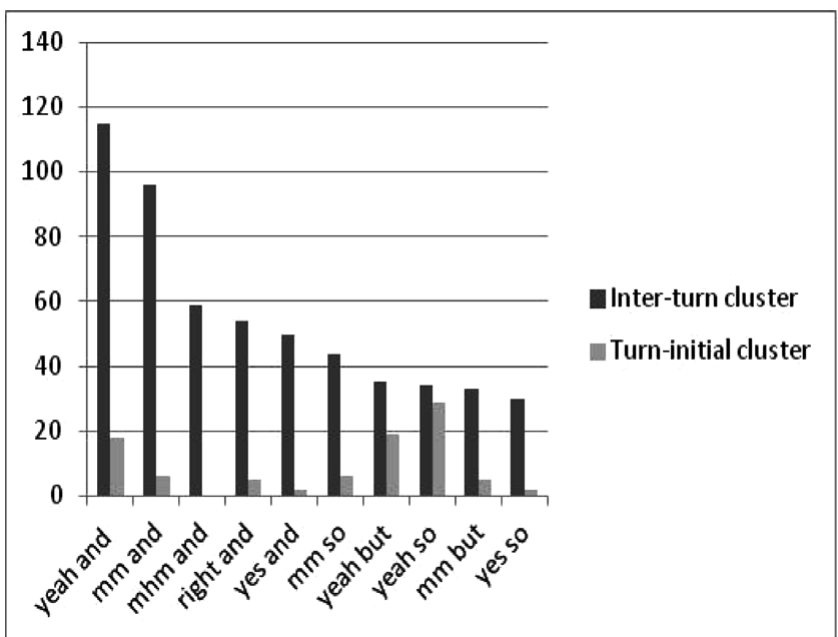

Figure 6 Inter-turn and intra-turn frequencies of clusters associated with textual turn-openers: raw frequency.

compared with casual conversation, they do regularly combine with turn-openers that have already been identified as having core discursive functions in academic encounters.

\subsection{Frequent turn-openers with less discursive specialisation}

This final section briefly considers three items which are high up the turn-opener frequency list in CANCAD but are not as frequent overall (per number of turns) compared with CANCSOC, and do not show as much discursive specialisation as the items discussed above. This does not mean they are not important discursive items, but that their behaviour in academic talk is more similar to their behaviour in the non-academic world. The most highly ranking turn-openers which show this distribution are well, no and oh, which rank eleventh, twelfth and fourteenth and in CANCAD, respectively (see Table 4). Their distribution across tutor and student talk, and compared with CANCSOC, can be seen in Figure 7.

We will focus here mainly on oh, which shows the most marked difference in frequency from casual talk of the three. As with Aijmer (1987) - a CL study of oh (and $a h$ ) in casual conversation - a range of functions was identified. Detailed analysis was carried out on all examples of turn-initial oh in CANCAD to see what kinds of academic activity it was associated with. The results of this analysis can be seen in Table 6 .

By way of exemplification, (8) shows part of a protracted discussion in a law seminar in which the tutor and student are disagreeing over a legal point. In this extract, we can see how the informal, conversational turn-opener oh yeah introduces an expanded tutor turn relating to their immediate teaching needs and works alongside lexis from a formal register (e.g. strict liability, defendant, duties of care) and the relatively formal, clause-length expression of argument what I'm saying to you is. 


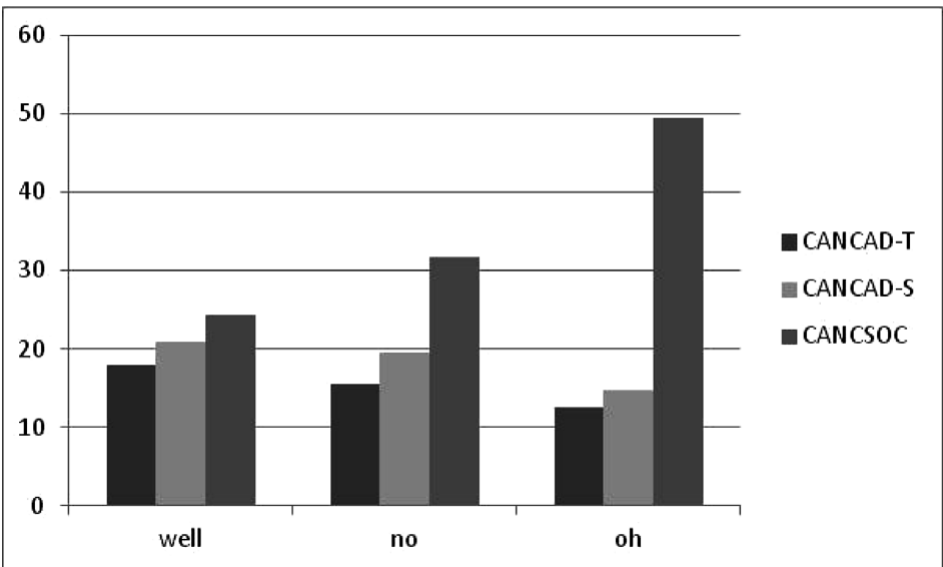

Figure 7 well, no and oh: frequency per $1 \mathrm{k}$ turns.

Table 6 Turn-initial oh: type of academic activity.

\begin{tabular}{|c|c|c|c|c|c|}
\hline & \multicolumn{2}{|c|}{ GANCAD-T } & \multicolumn{2}{|c|}{ GANCAD-S } & \multirow[b]{2}{*}{ Total } \\
\hline & $\begin{array}{l}\text { Short } \\
\text { turn }^{9}\end{array}$ & $\begin{array}{l}\text { Expanded } \\
\text { turn }\end{array}$ & $\begin{array}{l}\text { Short } \\
\text { turn }\end{array}$ & $\begin{array}{l}\text { Expanded } \\
\text { turn }\end{array}$ & \\
\hline $\begin{array}{l}\text { Opening turns relating to immediate } \\
\text { teaching/learning }\end{array}$ & 20 & 17 & 32 & 17 & 86 \\
\hline Opening turns relating to ongoing research/study & 15 & 5 & 16 & 3 & 39 \\
\hline Opening turns relating to practical matters & 5 & 9 & 6 & 8 & 28 \\
\hline Opening 'small talk' turns & 0 & 2 & 5 & 2 & 9 \\
\hline Unclassifiable & 3 & 3 & 9 & 5 & 20 \\
\hline Total & 43 & 36 & 68 & 35 & 182 \\
\hline
\end{tabular}

(8)

Turn SEM09

$1<\$ T>$ You're talking about strict liability?

$2<\$ S 4>$ Yeah. But before we studied that last year in the road accident we considered it would be erm er negligent under tort.

$3<\$ T>$ Oh yeah. But what I'm saying is that it's not really a context in which you're going to find the defendant having excluded his or her liability. What I'm saying to you is can you think of contexts with which duties of care are owed? There's no contract between the parties. [...]

We can see both no and oh exemplified in (9), where the student's segueing of relational talk into more transactional talk brings a tutorial to an end. This is reminiscent of the 'shading'

${ }^{9}$ Here, short turn refers to occurrences where oh occurs alone of as part of a short responsive contribution such as oh no. If any further content is added, a turn is considered to be expanded, as in oh no that's not what I meant (see McCarthy, 2002). 
of interpersonal talk into transactional in-service encounters put forward by Coupland and Ylänne-McEwan (2000) and further explored by McCarthy (2000) in relation to orientation to multiple goals in service encounters where relational concerns cannot be easily separated from the business of providing a service.

(9)

Turn File: IND01

$1<\$ T>[\ldots]$ Was it you who said wowser could mean exclamation mark?

$2<\$$ S $>$ No. But $<\$ G$ ? $>$

$3<\$ T>$ It was Oona wasn't it. Yes.

$4<\$ \mathrm{~S}><\$ \mathrm{E}>$ laughs $<\backslash \$ \mathrm{E}>$

$5<\$ \mathrm{~T}>$ Er em $<\$=>\mathrm{I}<\backslash \$=>$ I so I said to an American friend have you $<\$ \mathrm{G}$ ? $>$ it. Yes he said an exclamation mark. And yet to Australians it means em oh a puritanical old woman Yes.

$6<\$ \mathrm{~S}>$ Oh I see. Ooh. $<\$ \mathrm{E}>$ laughs $<\backslash \$ \mathrm{E}>\mathbf{O h} \mathrm{I}$ didn't know it was a word at all. $<\$ \mathrm{E}>$ laughs $<\backslash \$ E>$ except for an exclamation. All right then. Thank you very much.

$7<\$ T>$ Okay. So come back if you want further questions once you've got going on it.

$8<\$ \mathrm{~S}>$ Yeah. Okay. $<\$ \mathrm{E}>$ pause $<\backslash \$ \mathrm{E}>$ Bye-bye.

$9<\$ \mathrm{~T}>$ Bye.

This example shows that to see $o h$ 'simply' as one of a group of turn-openers associated with the talk of novices is too simplistic. Although $o h$ is more often uttered initially by students than by tutors, the difference in frequency across tutor and student turns is not great. It makes more sense to see $o h$, which occurs across all the activity types in CANCAD, as evidence of the unplanned, informal and 'involved' nature (Tannen 1984) of the discourse in CANCAD.

\section{Conclusion}

The analysis presented here has shown that turn-openings are important sites for the production of specialised discourse-level features that are as much concerned with the listener as with the speaker. However, speaking and listening still tend to be taught and assessed independently of each other on EAP (English for Academic Purposes) courses. Students are unlikely to have a great deal of time to experience interaction which involves the rapid exchange of turns with a power-role holder; ${ }^{10}$ speaking classes tend to rely on pair-work and group activities, which means that there is little opportunity to practise 'talking with a tutor'. More emphasis may, in fact, be put on relatively infrequent academic events which are perceived to cause anxiety - giving an individual presentation or reporting on a group project - but which do not require a great deal of locally managed turn-taking as the floor is generally given over to a nominated speaker. Likewise, listening practice tends to concentrate on improving the understanding of lectures, which means that students are relatively unlikely to have to talk as well as listen for sustained periods. Although this preoccupation with lectures reflects the 'traditional' worry expressed by international students of not being able

${ }^{10}$ The term power-role holder is used by O'Keeffe (2006) in relation to media interactions, but it is useful here as it can include tutors and/or people playing a tutor-like role. 
Page 20 of 24 JANE EVISON

to follow what their lecturers say (Flowerdew 1994), recent technological advances have made many aspects of lecture comprehension 'easier': visuals are much improved, handouts of speaker slides can be provided before or after lectures, and audio and video recordings are often made available as podcasts which can be replayed again and again. So, rather than separating the teaching of listening and speaking, the evidence presented in this paper suggests that their greater integration needs to be foregrounded, particularly in the form of one-to-one tutor/student interaction, or interaction which attempts to recreate this kind of dynamic.

As more and more people choose to study through the medium of English, the responsibility of the producers of high stakes 'gate-keeping' academic English language examinations to design tests such as IELTS (International English Language Testing System) that are as wellinformed of the realities of academic talk in its broadest sense increases. Rich descriptions of large datasets of spoken language are clearly needed to inform both teaching (in terms of pedagogy and the design of materials) and testing, and this is an area to which the English Profile Project can contribute - building on the kind of research into academic language presented here (and in Seedhouse [2012]), and looking at how students and tutors interact in a variety of output contexts. Such contexts should include all kinds of classrooms (not only academic ones), as well as out-of-class encounters, both educational (e.g. study groups) and those with more social aims. Such research could also contribute to an improved definition of 'interactional competence' (called for by Walsh [2012]) in which shared meaning-making in classroom contexts is conceptualised (Kramsch 1986; Young 2003). And, as with a more collaborative understanding of fluency (McCarthy 2010), a greater focus on identifying shared responsibilities in a range of contexts would help inform the CEFR level descriptors, which are currently largely oriented to individual speaker performance.

Finally, this paper has methodological implications: CL researchers should not rest on their laurels and search for things that are easy to find, nor should they avoid the importance of examining items in their discursive context. Turn-openings may exhibit regularity, but this regularity has to be searched for carefully and in a big enough sample. Whilst CL software can certainly be improved for the analysis of spoken language, the complex nature of turn-openings is still likely to require some manual analytical techniques; in order to ensure complex, subtle and above all accurate descriptions, so should it.

\section{Appendix 1 - Transcription information}

Transcription conventions used in the GANCODE corpus

\begin{tabular}{lcl}
\hline \hline Transcription convention & Symbol & \multicolumn{1}{c}{ Explanation } \\
\hline Filenames (abbreviation for ADE type & ALV & Class \\
plus number e.g. LEC01, LEC02, etc.) & GRP & Group tutorial \\
& IND & Individual tutorial \\
& LEC & Lecture \\
& SEM & Seminar \\
& SUP & Supervision \\
& UPG & PhD upgrade meeting \\
\hline \hline
\end{tabular}


UNDERSTANDING DISCURSIVE SPECIALISATION |Page 21 of 24

Appendix 1 - Continued

\begin{tabular}{|c|c|c|}
\hline Transcription convention & Symbol & Explanation \\
\hline \multirow[t]{2}{*}{ Speaker codes in CANCODE } & $<\$ 1>,<\$ 2>$, etc. & $\begin{array}{l}\text { Each speaker is numbered }<\$ 1>\text {, } \\
<\$ 2>\text {, etc. }\end{array}$ \\
\hline & $<\$ F ?>$ & $\begin{array}{l}\text { This code is used when the transcriber } \\
\text { is unsure about the speaker number. F } \\
\text { or M stand for female and male, } \\
\text { respectively. }\end{array}$ \\
\hline \multirow[t]{5}{*}{$\begin{array}{l}\text { Adapted speaker codes used in } \\
\text { CANCSOC }\end{array}$} & $<\$ \mathrm{~T}>$ & $\begin{array}{l}\text { Tutor (used when a single tutor was } \\
\text { present) }\end{array}$ \\
\hline & $<\$ \mathrm{~T} 1>,<\$ \mathrm{~T} 2>$ & $\begin{array}{l}\text { Tutor } 1 \text {, tutor } 2 \text { (used when more than } \\
\text { one tutor was present, the numbers } \\
\text { were assigned according to the order of } \\
\text { speaking and do not reflect a tutor's } \\
\text { status or role in the ADE). }\end{array}$ \\
\hline & $\begin{array}{l}<\$ \mathrm{~S} 1>,<\$ \mathrm{~S} 2> \\
<\$ \mathrm{~S} 3>\end{array}$ & $\begin{array}{l}\text { Student } 1 \text {, student } 2 \text {, student } 3 \text { (again, } \\
\text { numbers are attributed in order of } \\
\text { speakers). }\end{array}$ \\
\hline & $<\$ \mathrm{SF}>,<\$ \mathrm{SM}>$ & $\begin{array}{l}\text { These tags indicate the gender of the } \\
\text { speaker when their exact identity is not } \\
\text { known (this tends to happen in ADEs } \\
\text { where there are multiple speakers). }\end{array}$ \\
\hline & $<\$ \mathrm{~S}>$ & $\begin{array}{l}\text { This tag was used when transcribers } \\
\text { were unable to identify the } \\
\text { identity/gender of the student speaker } \\
\text { (again this tends to happen in ADEs } \\
\text { where there are multiple speakers). }\end{array}$ \\
\hline Extralinguistic information & $<\$ \mathrm{E}>\ldots</ \$ \mathrm{E}>$ & $\begin{array}{l}\text { This includes information added by } \\
\text { the transcriber, such as laughter, } \\
\text { coughing and inaudible speech. }\end{array}$ \\
\hline Latched utterance & + & $\begin{array}{l}\text { Instances marked by a }+ \text { at the point } \\
\text { where there is no perceivable gap } \\
\text { between one speaker's utterance and } \\
\text { another: } \\
<\$ 3>\text { Well I would suggest }+ \\
<\$ 1>\text { Monday. } \\
<\$ 3>+ \text { today you know }\end{array}$ \\
\hline $\begin{array}{l}\text { Unfinished sentence, repeat or false } \\
\text { start }\end{array}$ & $\begin{array}{l}<\$=>\ldots</ \$= \\
>\end{array}$ & $\begin{array}{l}\text { Anything that 'disturbs' the flow of the } \\
\text { discourse, such as repeated phrases } \\
\text { and false starts, as well as incomplete } \\
\text { utterances are marked as in the } \\
\text { example below: } \\
<\$=>\text { Do you }</ \$=>\text { Do you like } \\
\text { this? }\end{array}$ \\
\hline
\end{tabular}


Page 22 of 24 | JANE EVISON

\section{Appendix 1 - Continued}

\begin{tabular}{|c|c|c|}
\hline Transcription convention & Symbol & Explanation \\
\hline Unfinished words & $=$ & $\begin{array}{l}\text { Speakers not only change their course } \\
\text { in mid-utterance but also in the } \\
\text { middle of individual words, which is } \\
\text { marked as follows: } \\
\text { I th = I I I mean I could }\end{array}$ \\
\hline Guess & $<\$ H>\ldots</ \$ H>$ & $\begin{array}{l}\text { Utterances that are not entirely } \\
\text { inaudible can often be guessed from } \\
\text { the surrounding co-text. These } \\
\text { 'guesses' are marked thus: } \\
<\$ 6>\text { Well they call }<\$ H>\text { her } \\
</ \$ H>\text { Alison Sarah. }\end{array}$ \\
\hline Unintelligible & $\begin{array}{l}<\$ \mathrm{G} 3>,<\$ \mathrm{G} 2> \\
<\$ \mathrm{G} ?>\end{array}$ & $\begin{array}{l}\text { Especially in multi-party conversations } \\
\text { it is often difficult for the transcriber to } \\
\text { identify all utterances. If any utterance } \\
\text { or part of an utterance is unintelligible, } \\
\text { this is indicated by }<\$ G 3>\text { for } \\
\text { example where } 3 \text { equals } 3 \text { syllables or } \\
<\$ G \text { ? }>\text { where the number of syllables } \\
\text { cannot be identified: } \\
<\$ 1>\text { Alison. Is it? I've never }<\$ G 4>\text {. }\end{array}$ \\
\hline Punctuation & .? & $\begin{array}{l}\text { A full stop or question mark is used to } \\
\text { mark the end of a 'sentence' } \\
\text { (depending on intonation). A } \\
\text { 'sentence' is anything that is felt to be a } \\
\text { complete utterance, such as: } \\
<\$ 3>\text { I wouldn't have the energy. } \\
<\$ 1>\text { Good. } \\
\text { 'Good' is considered as a 'sentence' } \\
\text { here. } \\
\text { Unfinished 'sentences' are not followed } \\
\text { by a full stop. }\end{array}$ \\
\hline
\end{tabular}

\section{References}

Aijmer, K. (1987). Oh and ah in English conversation. In Meijs, W. (ed.), Corpus linguistics and beyond. Amsterdam: Rodopi, 61-86.

Biber, D. (2006). University language: A corpus-based study of spoken and written registers. Amsterdam: John Benjamins.

Blakemore, D. (2002). Relevance and linguistic meaning: The semantics and pragmatics of discourse markers. Cambridge: Cambridge University Press.

Brazil, D. (1995). A grammar of speech. Oxford: Oxford University Press.

Brown, G. and Yule, G. (1983). Discourse analysis. Cambridge: Cambridge University Press.

Buttery, P., Carter, R. \& McCarthy, M. (in press). Chatting in the academy: Informality in spoken academic discourse. 
Carter, R. A. (2004). Language and creativity: The art of common talk. London: Routledge.

Carter, R. and McCarthy, M. (1998). The English get passive in spoken discourse: Description and implications for interpersonal grammar. English Language and Linguistics 3.1, 41-58.

Carter, R. and McCarthy, M. (2006). The Cambridge grammar of English. Cambridge: Cambridge University Press.

Carter, R., McCarthy, M., Mark, G. \& O'Keeffe, A. (2011). English grammar today. Cambridge: Cambridge University Press.

Coupland, N. \& Ylänne-McEwan, V. (2000). Talk about the weather: Small talk, leisure talk and the travel industry. In Coupland, J. (ed.), Small talk. London: Longman, 163-182.

Csomay, E. (2007). A corpus-based look at linguistic variation in classroom interaction: Teacher talk versus student talk in American university classes. Fournal of English for Academic Purposes 6.4, 336355.

Duncan, S. (1972). Some signals and rules for taking speaking turns in conversation. Fournal of Personality and Social Psychology 23, 283-292.

Duncan, S. \& Niederehe, G. (1974). On signalling that it's your turn to speak. Fournal of Experimental Social Psychology 10.3, 234-247.

Evison, J. (2008). Turn-openers in academic talk: An exploration of discourse responsibility. Ph.D. thesis, University of Nottingham.

Evison, J. (2010). What are the basics of analysing a corpus? In McCarthy, M. \& O'Keeffe, A. (eds.), The Routledge handbook of corpus linguistics. London: Routledge, 122-135.

Evison, J., McCarthy, M. \& O'Keeffe, A. (2007). Looking out for love and all the rest of it: Vague category markers as shared social space. In Cutting, J. (ed.), Vague language explored. Basingstoke: Palgrave, 138-157.

Farr, F. (2003). Engaged listenership in spoken academic discourse: The case of student-tutor meetings. Journal of English for Academic Purposes 2.1, 67-85.

Flowerdew, J. (1994). Research of relevance to second language lecture comprehension - an overview. In Flowerdew, J. (ed.), Academic listening: Research perspectives. Cambridge: Cambridge University Press, $7-29$.

Fraser, B. (1990). An approach to discourse markers. Journal of Pragmatics 14: 383-398.

Fraser, B. (1999). What are discourse markers? Journal of Pragmatics 31, 931-952.

Gardner, R. (1987). The identification and role of topic in spoken interaction. Semiotica 65.1/2, 129141.

Gardner, R. (1997). The listener and minimal response in conversational interaction. Prospect 12.2, $12-32$.

Gardner, R. (2007). The right connections: Acknowledging epistemic progression in talk. Language in Society 36.3, 319-341.

Goffman, E. (1981). Forms of talk. Oxford: Basil Blackwell.

Goodwin, C. (1986). Between and within: Alternative sequential treatments of continuers and assessments. Human Studies 9, 205-217.

Hoey, M. (2005). Lexical priming: A new theory of words and language. London: Routledge.

Jacoby, S. \& Ochs, E. (1995). Co-construction: An introduction. Research on Language and Social Interaction $28,171-183$

Jucker, A. (1986). Newes interviewes: A pragmalinguistic analysis. Amsterdam: John Benjamins.

Kramsch, C. (1986). From language proficiency to interactional competence. Modern Language Fournal 70.4, 366-372.

McCarthy, M. (1998). Spoken language and applied linguistics. Cambridge: Cambridge University Press.

McCarthy, M. (2000). Captive audiences: Small talk and the genre of close-contact service encounters. In Coupland, J. (ed.), Small talk. London: Longman, 84-109.

McCarthy, M. (2002). Good listenership made plain: British and American non-minimal response tokens in everyday conversation. In Reppen, R., Fitzmaurice, S. \& Biber, D. (eds.), Using corpora to explore linguistic variation. Amsterdam: John Benjamins, 49-71.

McGarthy, M. (2003). Talking back: 'Small' interactional response tokens in everyday conversation. Research on Language in Social Interaction 36.1, 33-63.

McCarthy, M. (2010). Spoken fluency revisited. English Profile fournal 1.1, 1-15.

Nesi, H. \& Basturkmen, H. (2006). Lexical bundles and discourse signalling in academic lectures. International Fournal of Corpus Linguistics 11.3, 283-304. 
Page 24 of 24 JANE EVISON

O'Keeffe, A. (2006) Investigating media discourse. London: Routledge.

O'Keeffe, A. \& Adolphs, S. (2008). Using a corpus to look at variational pragmatics: Response tokens in British and Irish discourse. In Schneider, K. P. \& Barron, A. (eds.), Variational pragmatics. Amsterdam: John Benjamins, 69-98.

O'Keeffe, A., McCarthy, M. \& Carter, R. (2007). From corpus to classroom: Language use and language teaching. Cambridge: Cambridge University Press.

Poos, D. \& Simpson, R. C. (2002). Cross-disciplinary comparisons of hedging: Some findings from the Michigan Corpus of Academic Spoken English. In Reppen, R., Fitzmaurice, S. \& Biber, D. (eds.), Using corpora to explore linguistic variation. New York: John Benjamins, 3-23.

Sacks, H. (1992). Lectures on conversation (volumes I and II, edited by Jefferson, G.). Oxford: Blackwell.

Sacks, H., Schegloff, E. A. \& Jefferson, G. (1974). A simplest systematics for the organisation of turn-taking for conversation. Language 50.4, 696-735.

Schegloff, E. A. (1982). Discourse as an interactional achievement, some uses of 'uh huh' and other things that come between sentences. In Tannen, D. (ed.), Analyzing discourse: Text and talk. Washington, DC: Georgetown University Press, 71-93.

Schegloff, E. A. (1996). Turn organization: One intersection of grammar and interaction. In Ochs, E., Schegloff, E. A. \& Thompson, S. (eds.), Interaction and grammar. Cambridge: Cambridge University Press, 52-133.

Schiffrin, D. (1987). Discourse markers. Cambridge: Cambridge University Press.

Schiffrin, D. (2001). Discourse markers: Language, meaning, and context. In Schiffrin, D., Tannen, D. \& Hamilton, H. (eds.), The handbook of discourse analysis. Oxford: Blackwell, 54-75.

Schleef, E. (2009). A cross-cultural investigation of German and American academic style. Fournal of Pragmatics 41.6, 1104-1124.

Scott, M. (1999). Wordsmith Tools (software). Oxford: Oxford University Press

Seedhouuse, P. (2012). What kind of interaction receives high and low ratings in oral proficiency interviews? English Profile Journal 3.1, 1-24.

Sinclair, J. M. (1991). Corpus, concordance, collocation. Oxford: Oxford University Press.

Sinclair, J. M. \& Coulthard, M. (1975) Towards an analysis of discourse. Oxford: Oxford University Press. Stenström, A.-B. (1994). An introduction to spoken interaction. London: Longman.

Swales, J. M. \& Malczewski, B. (2001). Discourse management and new episode flags in MICASE. In Simpson, R. C. \& Swales, J. M. (eds.), Corpus linguistics in North America: Selections from the 1999 symposium. Michigan: University of Michigan, 145-164.

Tannen, D. (1984). Conversational style: Analyzing talk amongst friends. Norwood, NJ: Ablex Publishing Corporation.

Tao, H. (2003). Turn initiators in spoken English: A corpus-based approach to interaction and grammar. In Leistyna, P. \& Meyer, C. F. (eds.), Corpus analysis: Language structure and language use. Amsterdam: Rodopi, 187-207.

Tottie, G. (1991). Conversational style in British and American English: The case of backchannels. In Aijmer, K. \& Altenberg, B. (eds.), English corpus linguistics. London: Longman, 254-271.

Walsh, S. (2006). Analyzing classroom discourse: A variable approach. In Hughes, R. (ed.), Spoken English, TESOL and applied linguistics: Challenges for theory and practice. Basingstoke: Palgrave Macmillan, 216-239.

Walsh, S. (2012). Conceptualising classroom interactional competence. Novitas Royal 6.1, 1-14.

Yngve, V. (1970). On getting a word in edgewise. Papers from the 6th Regional Meeting, Chicago Linguistic Society. Chicago: Chicago Linguistic Society, 567-578.

Young, R. (2003). Learning to talk the talk and walk the walk: Interactional competence in academic spoken English. North Eastern Illinois University Working Papers in Linguistics 2, 26-44. 